\title{
Internal Dose from Food and Drink Ingestion in the Early Phase after the Accident
}

\author{
Masaki Kawai ${ }^{1, *}$, Nobuaki Yoshizawa ${ }^{1}$, Sachiko Hirakawa ${ }^{1}$, Kana Murakami ${ }^{1}$, Mari Takizawa ${ }^{1}$, Osamu Sato $^{1}$, Shunji \\ Takagi $^{1}$, Hirokazu Miyatake ${ }^{1}$, Tomoyuki Takahashi ${ }^{2}$ and Gen Suzuki ${ }^{3}$ \\ ${ }^{1}$ Mitsubishi Research Institute, Inc., 2-10-3, Nagata-cho, Chiyoda-ku, Tokyo, Japan \\ ${ }^{2}$ Kyoto University Research Reactor Institute, Asashironishi2-chome, Kumatori-machi, Sennan-gun, Osaka, Japan \\ ${ }^{3}$ International University of Health and Welfare Clinic, 2600-6, Kitakanemary, Otawara-city, Tochigi, Japan
}

\begin{abstract}
Activity concentrations in food and drink, represented by water and vegetables, have been monitored continuously since the Fukushima Daiichi Nuclear Power Plant accident, with a focus on radioactive cesium. On the other hand, iodine-131 was not measured systematically in the early phase after the accident. The activity concentrations of iodine-131 in food and drink are important to estimate internal exposure due to ingestion pathway. When the internal dose from ingestion in the evacuation areas is estimated, water is considered as the main ingestion pathway. In this study, we estimated the values of activity concentrations in water in the early phase after the accident, using a compartment model as an estimation method. The model uses measurement values of activity concentration and deposition rate of iodine-131 onto the ground, which is calculated from an atmospheric dispersion simulation. The model considers how drinking water would be affected by radionuclides deposited into water. We estimated the activity concentrations of water on Kawamata town and Minamisouma city during March of 2011 and the committed effective doses were $0.08 \mathrm{mSv}$ and $0.06 \mathrm{mSv}$. We calculated the transfer parameters in the model for estimating the activity concentrations in the areas with a small amount of measurement data. In addition, we estimated the committed effective doses from vegetables using atmospheric dispersion simulation and FARMLAND model in case of eating certain vegetables as option information.
\end{abstract}

\section{Introduction}

Radioactive materials were discharged into the atmosphere after the accident at Fukushima Daiichi Nuclear Power Plant of Tokyo Electric Power Company, resulted from the Great East Japan Earthquake which occurred on March 11, 2011. For health risk assessment to local residents, it is important to estimate how much radiation they were exposed to by radioactive materials.

There are two typical reports in the systematic dose estimation due to the accident by the following international institutions. World Health Organization (WHO) conducted a temporary evaluation using information obtained at that time and released a report with the aim of considering measures to reduce health effects of exposure to radiation through emergency response measures after the accident in 2012[1]. United Nations Scientific Committee on the Effects of Atomic Radiation (UNSCEAR), taking into consideration information within about two years after the accident, released a report in 2014. The report estimated more closely to the actual situation than that provided by WHO[2]. However, also in the evaluation of UNSCEAR, there are some factors of overestimation or underestimation due to uncertainty in source terms, lack of measured data on iodine-131 following the accident, etc. In order to obtain the accident impact regarding the internal dose from food ingestion, the survey of food supply in the early phase after the accident in Fukushima prefecture was investigated to provide information of the actual situation[3]. The investigation proves that there was less possibility of fresh vegetables or milk being widely supplied. The investigation also shows that tap water was used both for drinking and cooking. The report by WHO shows the estimation of internal dose in the early phase using the measured concentrations of foods. These data included the results of food samples collected just for monitoring purpose; therefore it might have led to an overestimation of representative dose. Internal dose due to tap water was not considered with the entire dose because the dose estimated with maximum detected levels was low in comparison with dose from other pathways. The report by UNSCEAR shows the estimation of the internal dose in the early phase after the accident using the activity concentrations of foods in IAEA/FAO database. The concentration data also included the results for identification of foods with the high concentrations. It appears to lead to overestimation of representative dose. Internal dose from tap water was estimated with the monitored data and consideration of restriction in the report.

Also, various studies of dose estimation from food after the accident have been published. Harada et al. estimated internal doses for residents in three areas: village of Kawauchi, Tamano area of Soma and Haramachi area of Minamisoma, during August-

Corresponding author: makawai@mri.co.jp 
September 2012 by food-duplicate survey[4]. The internal dose estimated from dietary intake of radioactive cesium averaged $0.0058,0.019$ and $0.0088 \mathrm{mSv} / \mathrm{y}$. The authors pointed out that the survey cannot consider day to day variation in individuals as an uncertainty and the result does not include the dose from iodine-131 in the early phase. Tsutsumi et al. estimated the committed effective dose from ingestion using market basket method in three prefectures: Tokyo, Miyagi and Fukushima[5]. The food for dose estimation was collected in each prefecture in autumn 2011 and the estimated doses of radioactive cesium were $0.021,0.017$ and $0.019 \mathrm{mSv} /$ year. They noted that the doses were significantly lower than the maximum permissible dose ( $1 \mathrm{mSv} /$ year) determined by the Ministry of Health, Labour and Welfare, Japan. Yamaguchi et al. reported the results of dose estimation based on the monitoring data of activity concentration in food from the early phase after the accident through December $2012^{6)}$. They estimated the committed effective dose from iodine-131 and radioactive cesium in food by age group. The highest median value was $0.19 \mathrm{mSv}$ in children $13-18$ years of age. They mentioned some factors of overestimation or underestimation such as effectiveness restrictions to food.

Taking into account the international reports and these studies, we considered an estimation method of Iodine-131 concentrations in tap water for dose estimation. As for vegetables, we considered an estimation method of concentration to calculate the internal dose from the intake of vegetables which might have been consumed.

In this study, the estimation mainly covered near the evacuation areas, where estimating the dose was considered to be particularly important in the early phase. For reference, we used the results of WSPEEDI established by the Japan Atomic Energy Agency (JAEA), National Research and Development Agency, in order to obtain deposition rate[7].

\section{Methods}

\subsection{Estimation Method for lodine-131 Concentration of Tap Water}

To estimate iodine-131 concentration of tap water, we used a compartment model where radionuclides contained in tap water are deemed to attenuate at a fixed rate to their concentration, and increase at every new depositions. In estimating iodine-131 concentration of tap water through the compartment model, changes of activity concentration in tap water are represented by the rate of radionuclides newly deposited into water and effective attenuation of radionuclides contained in water,

$$
\frac{\mathrm{d} C}{\mathrm{~d} t}=p-\lambda C
$$

Where $C$ is the iodine-131 concentration in tap water $(\mathrm{Bq} / \mathrm{kg}), p$ is the rate of deposition into water $(\mathrm{Bq} / \mathrm{kg}$. hour), and $\lambda$ is the effective attenuation coefficient (1/hour).

Formula (1) can be represented as follows, provided the rate of deposition into water is replaced by the rate of radionuclides deposition onto the ground, which is calculated using an atmospheric dispersion simulation and conversion coefficient.

$$
\begin{aligned}
& \frac{\mathrm{d} C}{\mathrm{~d} t}=a p^{\prime}-\lambda C \\
& \left(p=a p^{\prime}\right)
\end{aligned}
$$

Where $p^{\prime}=$ rate of iodine-131 deposition onto the ground, which is calculated with an atmospheric dispersion simulation $\left(\mathrm{Bq} / \mathrm{m}^{2} \cdot\right.$ hour $)$, and $\mathrm{a}=$ conversion coefficient $\left(\mathrm{m}^{2} / \mathrm{kg}\right)$.

Conversion coefficient and effective attenuation coefficient are determined using the least squares method and finding the best fit, substituting measurement values of iodine-131 concentration in tap water. The optimal value of the concentration can be estimated with the parameters.

Based on this estimation method, data necessary for estimating iodine-131 concentration in water are iodine-131 concentration values actually measured in water and the deposition rate onto the ground calculated from an atmospheric dispersion simulation. The deposition rate onto the ground was calculated by total ground depositions at a time step and a next time step by WSPEEDI. As for measurement values of iodine-131 concentration, we collected data contained in publiclyavailable information, which was obtained at water purifying facilities or drinking spaces of running water at local municipal offices[8]. In addition, tap water travels until it reaches each drinking space, starting from the source of tap water, then on to a purifying facility and a distribution facility. Radionuclides in the atmosphere are more likely to deposit into water at the source and at some parts of a water purifying facility, via these relay points. Water distributed through a water purifying facility to each household, on the other hand, seems less affected by radionuclides deposition because most of the tap water piping goes under the ground or indoor. Taking into account these conditions, the water source is deemed to be the place where radionuclides are deposited, when the deposition rate onto the ground is calculated from an atmospheric dispersion simulation. When the location of water source is not identified, a purifying facility is substituted. It is assumed that it takes twelve hours for tap water to be taken in after the deposition of radionuclides. In other words, the activity concentration in tap water at a time affected by the depotion rate onto the ground in the water source at 12 hours before.

\subsection{Dose Estimation from Intake of Tap water}

The effective dose of iodine-131 was estimated as;

$$
\operatorname{Dose}(S v)=A \times B \times \sum_{t} \bar{C}_{t}
$$


where $A$ is the coefficient for iodine-131 ( $\mathrm{Sv} / \mathrm{Bq}), B$ is the daily consumption of water $(\mathrm{kg} / \mathrm{day}), t$ is the number of days and $\bar{C}$ is the daily mean concentration of iodine131 in water at $t(\mathrm{~Bq} / \mathrm{kg})$.

The coefficient is reference value from the publications of the International Commission on Radiological Protection (ICRP)[9]. Assuming the water intake volume in the early phase after the accident, the impact of the earthquake disaster should be considered. In some cases, the evacuees obtained bottled water for drink in this phase[10]. The bottled water can be regarded as unconcentrated water; therefore the bottled water volume was not added for dose estimation in this study. On the other hand, tap water which may be utilized for cooking and some amount of drink should be considered in water intake volume for dose estimation. The media volume of water intake for evacuees in Fukushima prefecture was assumed be $1.2 \mathrm{~L}$ /day based on hearing survey results. The median volume for nonevacuees was assumed to be $1.8 \mathrm{~L} /$ day based on existing inquiry results[11].

Activity concentrations in water have been generally measured since the accident. The restriction was requested according to the index values for the restriction on the intake of food and beverages set out by the Nuclear Safety Commission when the activity concentration was high. For example, on March 21, 2011 , the activity concentration in tap water of the small-scale water supply in Iitate village exceeded the index value for restriction and Fukushima prefecture informed the residents using the tap water to refrain from drinking water[12]. In consideration of these actual situations about water, the activity concentration in water was determined by following the chart below.

$C$ in the target area at the target day.

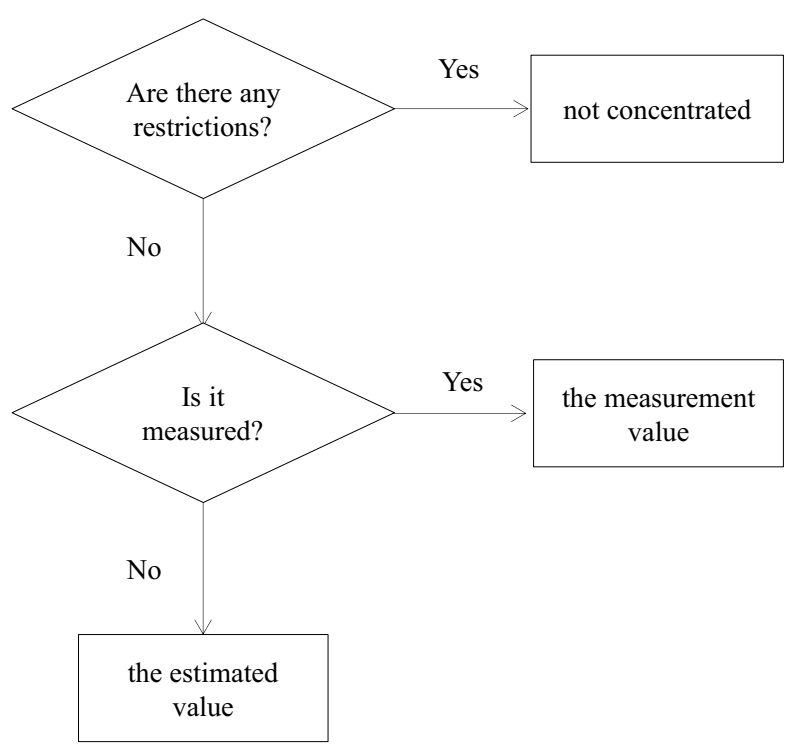

Fig. 1. Flow chart for concentration of water

\subsection{Estimation Method for Concentration of Vegetables}

In order to estimate the internal dose from intake of vegetables immediately after the accident, activity concentrations of vegetables were estimated using FARMLAND model. FARMLAND model is utilized to predict the transfer of radionuclides into foods such as green vegetables, root vegetables, grain and cow milk, by deposition onto the ground ${ }^{13}$. In this model, the movement of radionuclides within each module is represented by transfers between interconnected compartments and within each module it is assumed that first-order kinetics apply. The model set the specific parameter in each model of vegetables such as green vegetables and root vegetables. In this study, the activity concentrations of vegetables were estimated by these parameters ${ }^{14)}$. The depositions onto the ground and the vegetables were calculated using the deposition rates by WSPEEDI and interception factor. Fig. 2 shows the concept for estimation of activity concentration in vegetables.

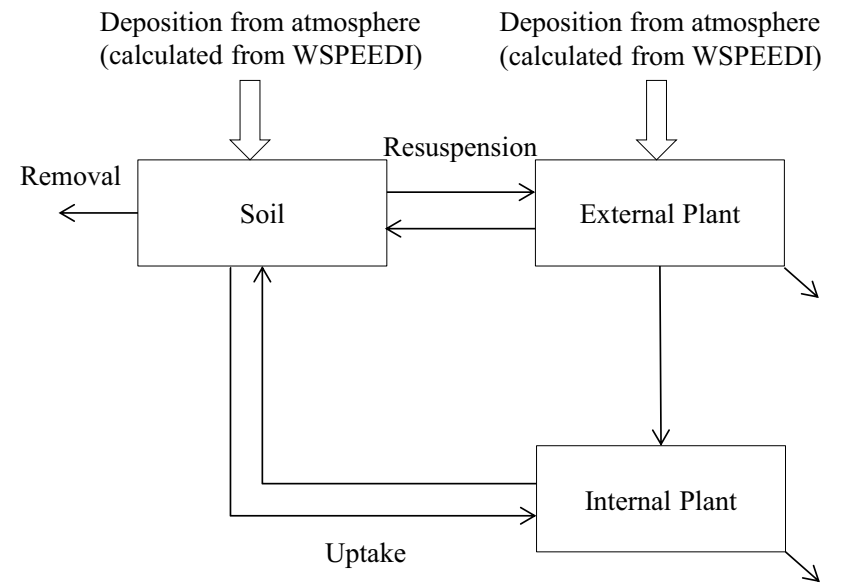

Fig. 2. Concept for estimation of concentration in vegetables

Ministry of Health, Labour and Welfare publishes activity concentrations in food including vegetables measured by various facilities immediately after the accident ${ }^{15)}$. We estimated the concentrations on the areas where there were measurements, to discuss the result of this model. However, it is difficult to obtain the details of the locations. Therefore, the location of each municipal office was substituted for that of planting and the deposition onto the ground of the location by WSPEEDI was used for estimation.

\subsection{Dose Estimation from Intake of Vegetables}

Considering the dose estimation from intake of vegetables in the early phase after the accident, the impact of the earthquake disaster should be considered. In particular, evacuees did not generally take the concentrated vegetables in refuge life. However, any residents may take the outdoor-grown vegetables. In this case, if the intake amount of the vegetables is calculated by general intake amounts of Japanese, the amount does 
not reflect the situation in the term. Therefore, we provide the dose estimated by an amount of radionuclides per $100 \mathrm{~g}$ of a vegetable taking as option information. The effective dose from certain vegetables per $100 \mathrm{~g}$ was estimated as;

$$
\operatorname{Dose}(S v / k g)=A_{k} \times C_{k, i, t}
$$

where $k$ is the radionuclide, $A_{k}$ is the coefficient for radionuclide $k(\mathrm{~Sv} / \mathrm{Bq}), t$ is the number of days, $i$ is the kind of vegetable and $C_{k, i, t}$ is the concentration of radionuclide $k$ at $t$.

\section{Results}

\subsection{Tap Water}

We estimated the activity concentrations of water in the areas where there had been measurements in the early phase after the accident. Fig. 3 and Fig. 4 show the estimation results using the measurement values on Kawamata town and Minamisouma city.

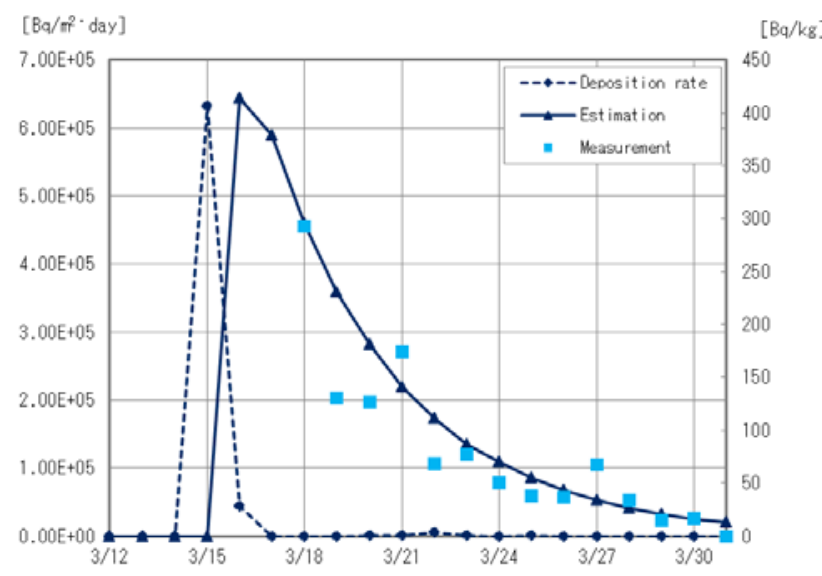

Fig. 3. Estimation Result of Tap Water on Kawamata town. The points indicate the measument values, the line the esitamed values and the broken line the deposition rate calculated by WSPEEDI.

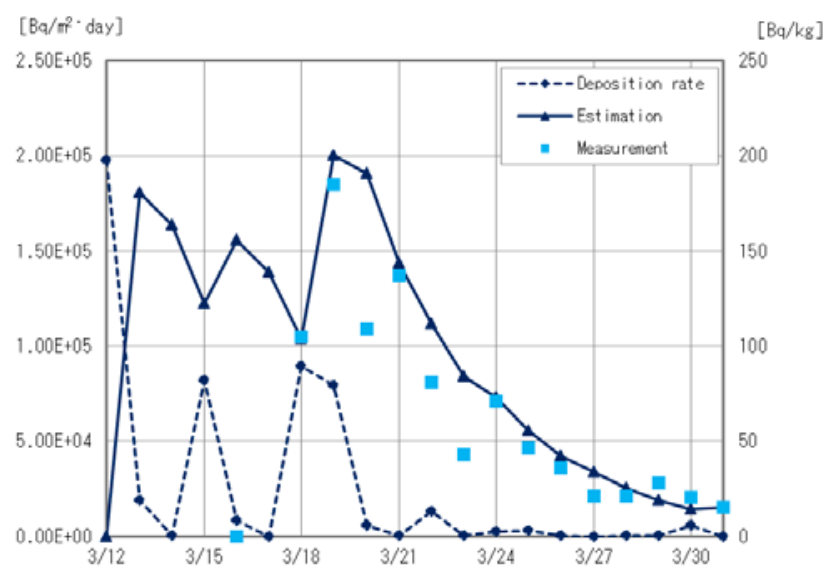

Fig. 4. Estimation Result of Tap Water on Minamisoma city. The points indicate the measument values, the line the esitamed values and the broken line the deposition rate calculated by WSPEEDI.
Table 1 shows the committed effective dose of adult evacuees and adult non-evacuees from water.

Table 1. Committed effective dose from water based on the measured concentration, the estimated concentration and

the assumed intake volume on Kawamata town and

Minamisoma city during March of 2011 (mSv).

\begin{tabular}{|c|c|c|}
\hline & $\begin{array}{c}\text { Dose for } \\
\text { evacuee }\end{array}$ & $\begin{array}{c}\text { Dose for non- } \\
\text { evacuee }\end{array}$ \\
\hline Kawamata town & 0.05 & 0.08 \\
\hline Minamisoma city & 0.04 & 0.06 \\
\hline
\end{tabular}

Fig. 5 and Fig. 6 show the parameters of conversion coefficients and of effective attenuation coefficients in the areas where the activity concentrations was measured.

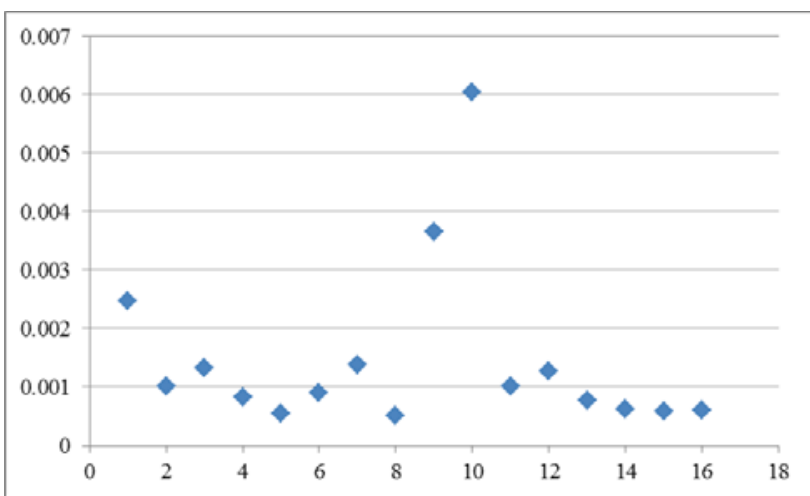

Fig. 5. Parameters of conversion coefficients on various areas.

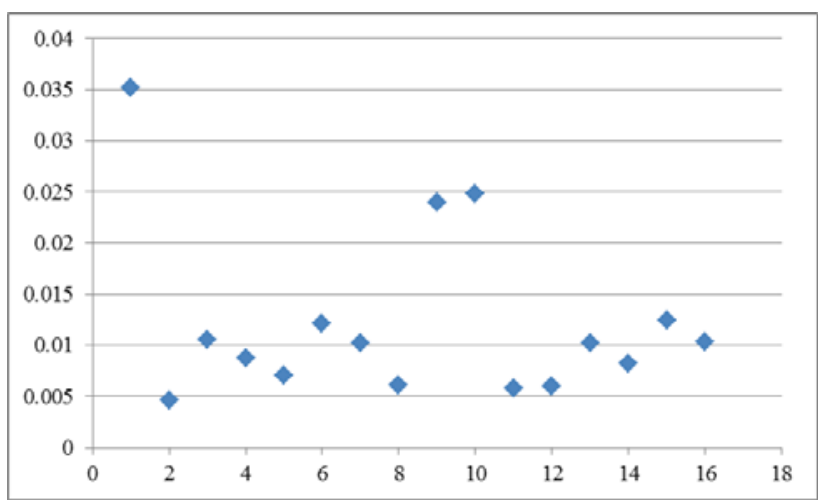

Fig. 6. Parameters of effective attenuation coefficients on various areas.

The mean value of conversion coefficients and of effective attenuation coefficients are 0.0015 and 0.012 .

\subsection{Vegetables}

We estimated activity concentrations of vegetables using deposition rates obtained by WSPEEDI. Table 2 and Table 3 show the concentrations of spinach and cabbage measured on March 28, 2011 and the estimated concentrations. 
Table 2. Activity concentration for spinach $(\mathrm{Bq} / \mathbf{k g})$.

\begin{tabular}{|c|c|c|c|c|}
\hline \multirow{2}{*}{ Location } & \multicolumn{2}{|c|}{$\begin{array}{c}\text { Activity } \\
\text { concentration } \\
\text { (Measured value) }\end{array}$} & \multicolumn{2}{|c|}{$\begin{array}{c}\text { Activity } \\
\text { concentration } \\
\text { (Estimated value) }\end{array}$} \\
\hline & ${ }^{131} \mathrm{I}$ & ${ }^{137} \mathrm{Cs}$ & ${ }^{131} \mathrm{I}$ & ${ }^{137} \mathrm{Cs}$ \\
\hline $\begin{array}{l}\text { Izumizaki } \\
\text { village }\end{array}$ & 3500 & 4700 & 26000 & 18000 \\
\hline $\begin{array}{l}\text { Otama } \\
\text { village }\end{array}$ & 5900 & 17000 & 2500 & 1200 \\
\hline Ono town & 5100 & 2300 & 6000 & 3200 \\
\hline $\begin{array}{l}\text { Tanagura } \\
\text { town }\end{array}$ & 2700 & 3100 & 7100 & 3800 \\
\hline $\begin{array}{c}\text { Tamura } \\
\text { city }\end{array}$ & 8400 & 8400 & 21000 & 13000 \\
\hline $\begin{array}{l}\text { Nakajima } \\
\text { village }\end{array}$ & 2300 & 1100 & 17000 & 11000 \\
\hline $\begin{array}{c}\text { Hanawa } \\
\text { town }\end{array}$ & 2100 & 830 & 4000 & 2500 \\
\hline $\begin{array}{l}\text { Hirata } \\
\text { village }\end{array}$ & 5300 & 460 & 9000 & 31 \\
\hline $\begin{array}{l}\text { Yabuki } \\
\text { Town }\end{array}$ & 1600 & 320 & 18000 & 12000 \\
\hline $\begin{array}{l}\text { Yabuki } \\
\text { Town }\end{array}$ & 2000 & 400 & 18000 & 12000 \\
\hline
\end{tabular}

Table 3. Activity concentration for cabbage (Bq/kg).

\begin{tabular}{|c|c|c|c|c|}
\hline \multirow[t]{2}{*}{ Location } & \multicolumn{2}{|c|}{$\begin{array}{c}\text { Activity } \\
\text { concentration } \\
\text { (Measured value) }\end{array}$} & \multicolumn{2}{|c|}{$\begin{array}{c}\text { Activity } \\
\text { concentration } \\
\text { (Estimated value) } \\
\end{array}$} \\
\hline & ${ }^{131} \mathrm{I}$ & ${ }^{137} \mathrm{Cs}$ & ${ }^{131} \mathrm{I}$ & ${ }^{137} \mathrm{Cs}$ \\
\hline $\begin{array}{c}\text { Asakawa } \\
\text { town }\end{array}$ & 1100 & 1400 & 2600 & 1800 \\
\hline $\begin{array}{l}\text { Ishikawa } \\
\text { town }\end{array}$ & 12 & 0 & 2100 & 1600 \\
\hline $\begin{array}{c}\text { Minamisou } \\
\text { ma city }\end{array}$ & 140 & 51 & 8000 & 6800 \\
\hline
\end{tabular}

Table 4 shows the committed effective dose from cabbage and spinach by $100 \mathrm{~g}$ ingestion in Table 2 and Table 3. The dose were estimated by contributions of ${ }^{131} \mathrm{I},{ }^{134} \mathrm{Cs}$ and ${ }^{137} \mathrm{Cs}$.

Table 4. Estimation of committed effective dose from spinach (mSv/100g).

\begin{tabular}{|c|c|c|}
\hline \multirow{2}{*}{ Location } & $\begin{array}{c}\text { Committed } \\
\text { effective dose } \\
\text { (By measured } \\
\text { concentration) }\end{array}$ & $\begin{array}{c}\text { Committed } \\
\text { effective dose } \\
\text { (By estimated } \\
\text { concentration) }\end{array}$ \\
\hline Izumizaki village & 0.02 & 0.1 \\
\hline Otama village & 0.07 & 0.009 \\
\hline Ono town & 0.02 & 0.02 \\
\hline
\end{tabular}

\begin{tabular}{|c|c|c|}
\hline Tanagura town & 0.02 & 0.03 \\
\hline Tamura city & 0.05 & 0.09 \\
\hline Nakajima village & 0.008 & 0.07 \\
\hline Hanawa town & 0.007 & 0.02 \\
\hline Hirata village & 0.01 & 0.03 \\
\hline Yabuki Town & 0.004 & 0.08 \\
\hline Yabuki Town & 0.006 & 0.08 \\
\hline
\end{tabular}

Table. 5 Estimation of committed dose from cabbage (mSv/100g)

\begin{tabular}{|c|c|c|}
\hline \multicolumn{2}{|c}{$(\mathbf{m S v} / \mathbf{1 0 0 g})$} \\
\hline Location & $\begin{array}{c}\text { Committed } \\
\text { effective dose } \\
\text { (By measured } \\
\text { concentration) }\end{array}$ & $\begin{array}{c}\text { Committed } \\
\text { effective dose } \\
\text { (By esitmated } \\
\text { concentration) }\end{array}$ \\
\hline Asakawa town & 0.007 & 0.01 \\
\hline Ishikawa town & 0.00003 & 0.01 \\
\hline $\begin{array}{c}\text { Minamisouma } \\
\text { city }\end{array}$ & 0.0005 & 0.04 \\
\hline
\end{tabular}

\section{Discussions}

The estimation results of activity concentration in tap water was in good agreement with the concentration measured in Kawamata town and Minamisouma city. These results proved that the activity concentration in tap water can be estimated by the rate of iodine-131 deposition onto the ground from an atmopspheric dispersion simlation. The committed doses were lower than the maximum permissible dose $1 \mathrm{mSv} / \mathrm{year}$, however, considering the results of the other researches for dose estimation, the dose cannot be ignored. For the areas without actual measurement data of activity concentration in water, though, either conversion coefficients or effective attenuation coefficients cannot be determined by the measured concentration. In this case, the average values of conversion coefficients and effective attenuation coefficients, which were obtained from those of areas with measured concentration, were used for supposition of coefficients to estimate activity concentration for the areas without measured data. As a factor of overestimation or underestimation, the water intake volumes for evacuee and non-evacuee vary, though we set the values of both. In addition, the facility effect of a water purifying facility is factored into parameters such as conversion coefficients in this model using measurement values, as some reports mentioned that it can reduce the influence of iodine-131.

For vegetables, the result shows that the activity concentration and the dose can be estimated by this model at a certain day in the early phase after the 
accident. These vegetables measured for the activity concentration were non-distributed food because of the ristriction of distribution. Due to that, the vegetables evaluated in this study were seemed to be rarely eaten. It is neccessary to adjust the parameters in the model because the concentrations of cabbage seemed to be overestimated in comparison with the measured concentration. Though we estimated two kinds of vegetables in this estimation, the estimations will be improved more appropriate to the reality by hearing survey about what the evacuees ate.

The values of activity concentrations in water and vegetables will change according to the improvement of the atmospheric dispersion simulation, WSPEEDI. Therefore, if WSPEEDI is improved, we will provide more accurate doses in the early phase. On the other hand, the estimated values may change according to different distance, because the deposition rate after the accident varies considerably, despite being merely several kilometers apart. The errors of these results vary due to the errors of the deposition rates by WSPEEDI, therefore we will consider the uncertainty for dose estimation including that of WSPEEDI. Finally, the results may help the dose estimation of the actual situation in the early phase after the accident by reducing these uncertainties.

\section{References}

1. WHO, Preliminary dose estimation from the nuclear accident after the 2011 Great East Japan Earthquake and Tsunami (2012).

2. UNCEAR, UNSCEAR 2013 Report to the General Assembly with scientific annexes (2014).

3. Hirakawa S., et al., "Surveys of Food Distribution Just after the Nuclear Accident and Challenges", Journal of Japan Society for Safety Engineering, 53(3), p167-p172, 2014(in japanese).

4. Harada, K.H., T. Niisoe, M. Imanaka et al., "Radiation dose rates now and in the future for residents neighboring restricted areas of the Fukushima Daiichi Nuclear Power Plant.” Proc Natl Acad Sci U S A 111(10): E914-923 (2014).

5. Tsutumi T., et al., "Estimation of the Committed Effective Dose of Radioactive Cesium and Potassium by the Market Basket Method", Journal of the Food Hygienic Society of Japan, 54(1), p7- 13, 2013(in japanese).

6. Yamaguchi I., et al., "Dose estimation from food intake due to the Fukushima Daiichi nuclear power plant accident”, 62(2), p138-143, 2013 (in japanese).

7. Terada H., et al., "Development of worldwide version of system for prediction of environmental emergency dose information: WSPEEDI 2nd version", Journal of the Atomic Energy Society of Japan, 7, p257-p267, 2008 (in japanese).

8. Ministry of Health, Labour and Welfare, "The Survey Results of Radioactive Materials in Tap Water" (in japanese) Available at : $<$ http://www.mhlw.go.jp/file/06-Seisakujouhou10900000-
Kenkoukyoku/1_houshasei_110719_m1.pdf> [Accessed 23 Aügust 2016]

9. ICRP, "Compendium of Dose Coefficients based on ICRP Publication 60", ICRP Publication 119. 2012.

10. Iitate Village, "Record of Devastation from the Great East Japan Earthquake and TEPCO Fukushima Daiichi Nuclear Power Station Accident (First Edition) - Progress Made in the First Two Years after the Disaster", 2013(in japanese). Available at :

$<$ http://archive.vill.iitate.fukushima.jp/dsearch/ics/vie w_data.php?dataId $=0005639>\quad$ [Accessed 23 August 2016]

11. Health, labour and science research grant "Comprehensive study on risk evaluation and control of water quality in tap water" Contribution section meeting report(in japanese).

12. Ministry of Health, Labour and Welfare press release, 2011. Available at : $<$ http://www.mhlw.go.jp/english/policy/health/water _supply/d1/7-1_march_21_02.pdf $>$ [Accessed 23 August 2016]

13. Brown J. and Simmonds J. R., "FARMLAND: a dynamic model for the transfer of radionuclides through terrestrial foodchains. National Radiological Protection Board.”, NRPB-R273, 1995.

14. Sherwood J. (private communication).

15. Ministry of Health, Labour and Welfare, "Database of radioactive substances in food". Available at: $<$ http://www.radioactivity-db.info/search.aspx $>$ [Accessed 23 August 2016] 